\title{
Photophysical Properties of Anthanthrene-Based Tunable Blue Emitters
}

\author{
Bipin K. Shah,* Douglas C. Neckers* \\ Center for Photochemical Sciences, Bowling Green State University, Bowling Green, \\ Ohio 43402 \\ Jianmin Shi, * Eric W. Forsythe, David Morton \\ U. S. Army Research Laboratory, AMSRD-SE-EO, 2800 Power Mill Road, Adelphi, \\ Maryland 20783 \\ bipin@bgnet.bgsu.edu; neckers@photo.bgsu.edu; jshi@arl.army.mil
}

\section{Supporting Information}

Fig. S1. HOMO and LUMO molecular orbitals of 1 calculated by DFT.

Fig. S2. The DFT optimized structures of 4 and 6.

Fig. S3-4. Absorpton and fluorescence spectra of 1 recorded in different solvents.

Fig. S5. Absorpton spectra of 3 and 5 recorded in $\mathrm{CH}_{2} \mathrm{Cl}_{2}$.

Fig. S6. Fluorescence spectrum of 4 recorded in $\mathrm{CH}_{2} \mathrm{Cl}_{2}$.

Fig. S7-S14. Fluorescence decay profiles and cyclic voltammetry graphs. 
(a)

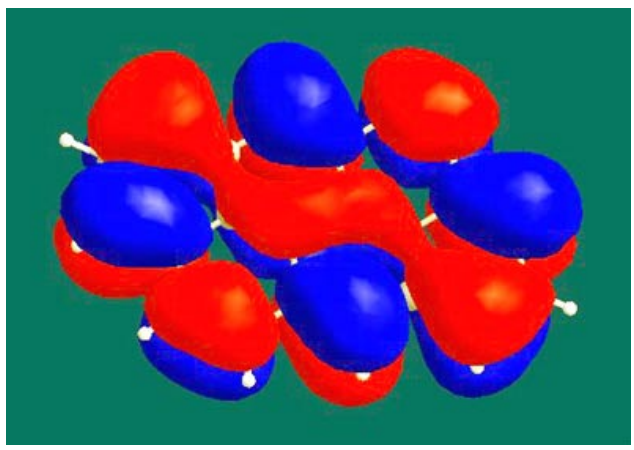

(b)

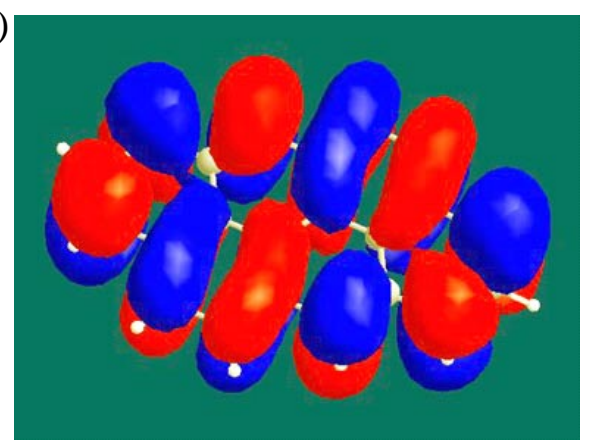

Figure S1. (a) HOMO and (b) LUMO molecular orbitals of 1 as calculated by DFT using B3LYP/6-31G* level of basis sets.

(a)

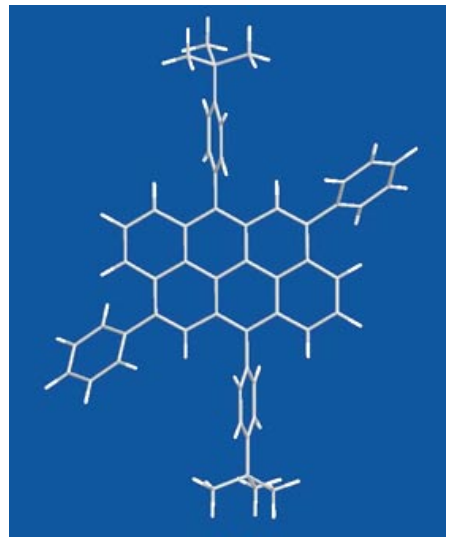

(b)

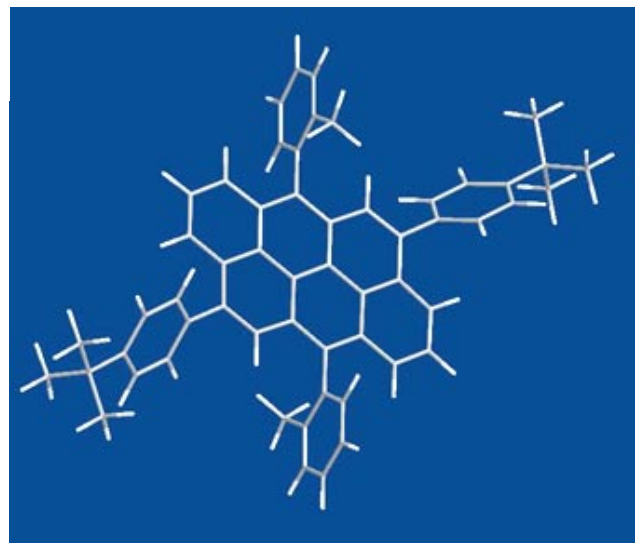

Figure S2. The geometry optimized structures of (a) 4 and (b) 6 by DFT using B3LYP/6$31 \mathrm{G}^{*}$ level of basis sets. 


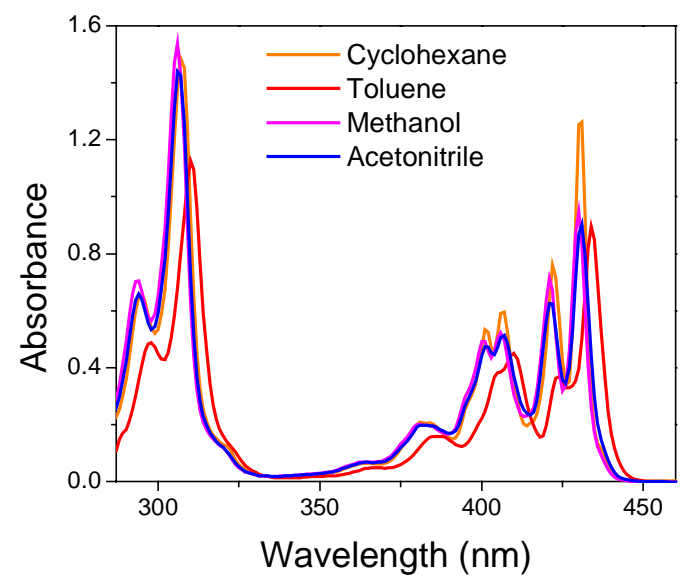

Figure S3. Absorption spectra of 1 recorded in different solvents.

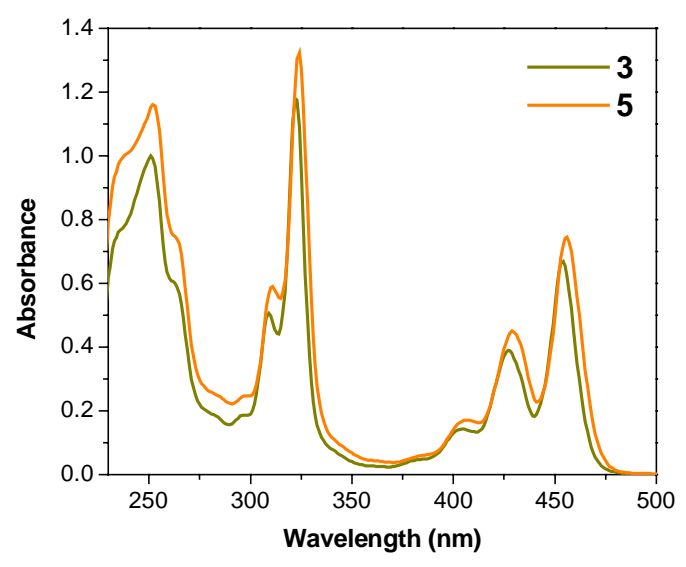

Figure S5. Absorption spectra of $\mathbf{3}$ and $\mathbf{5}$ recorded in $\mathrm{CH}_{2} \mathrm{Cl}_{2}$.

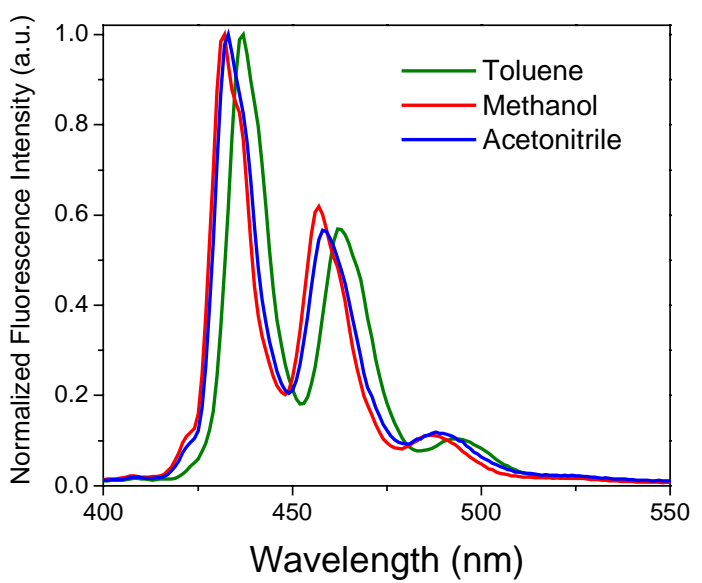

Figure S4. Fluorescence spectra of 1 recorded in different solvents.

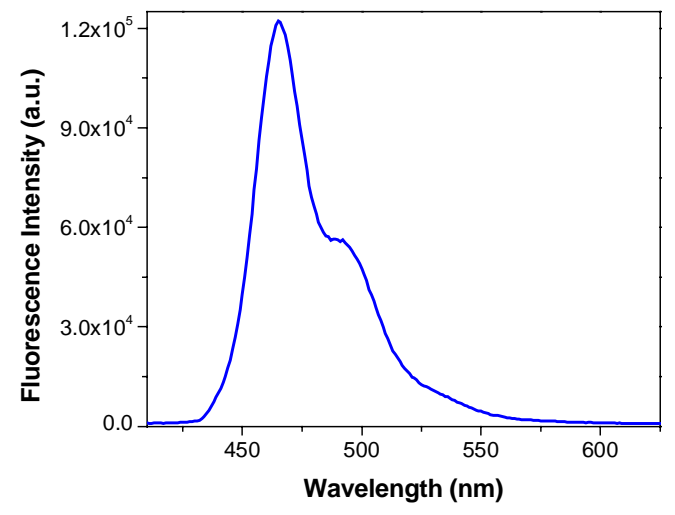

Figure S6. Fluorescence spectrum of $\mathbf{4}$ recorded in $\mathrm{CH}_{2} \mathrm{Cl}_{2}$. 


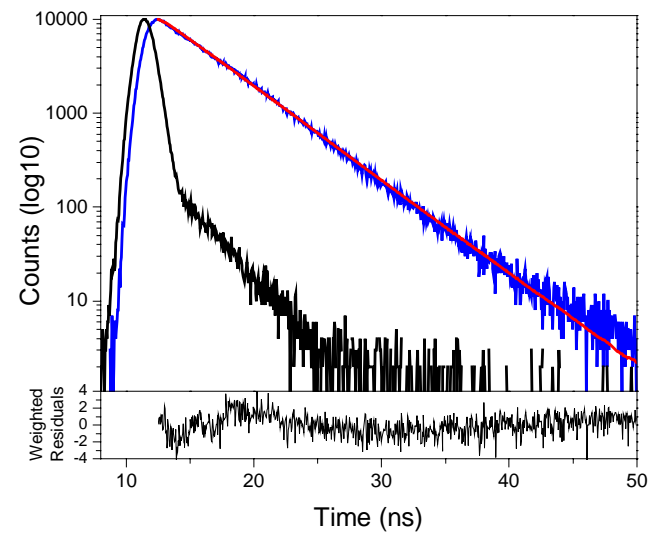

Figure S7. Decay of fluorescence of $\mathbf{2}$ monitored at $442 \mathrm{~nm}$ (solv.- $\left.\mathrm{CH}_{2} \mathrm{Cl}_{2}\right)\left(\chi^{2}\right.$ $=1.51)$.

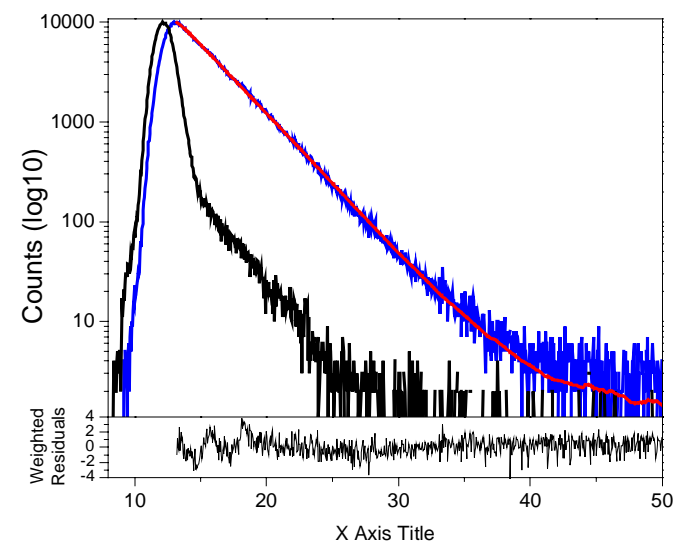

Figure S8. Decay of fluorescence of $\mathbf{3}$ monitored at $462 \mathrm{~nm}$ (solv.- $\left.\mathrm{CH}_{2} \mathrm{Cl}_{2}\right)\left(\chi^{2}\right.$ $=1.32$ ).

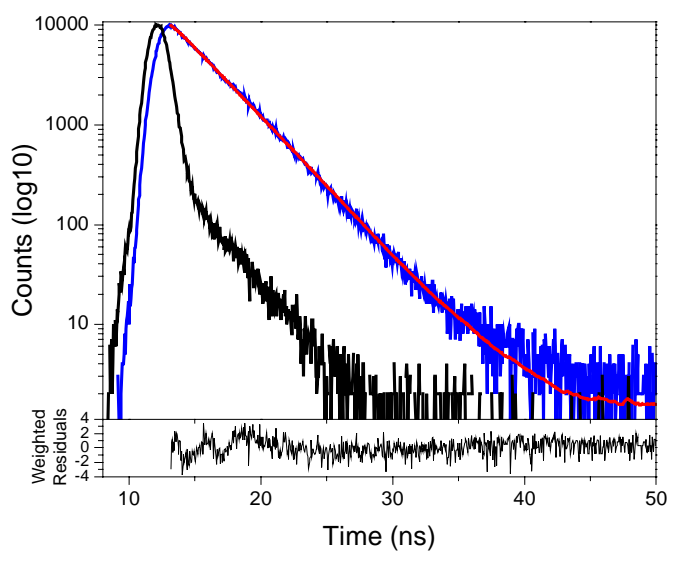

Figure S9. Decay of fluorescence of 4 monitored at $465 \mathrm{~nm}$ (solv.- $\left.\mathrm{CH}_{2} \mathrm{Cl}_{2}\right)\left(\chi^{2}\right.$ $=1.27$ ).

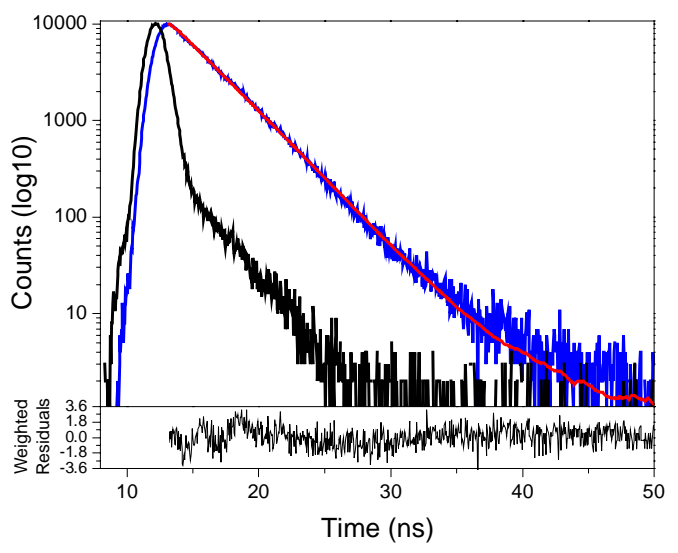

Figure S10. Decay of fluorescence of 5 monitored at $467 \mathrm{~nm}$ (solv.- $\left.\mathrm{CH}_{2} \mathrm{Cl}_{2}\right)\left(\chi^{2}\right.$ $=1.35)$. 


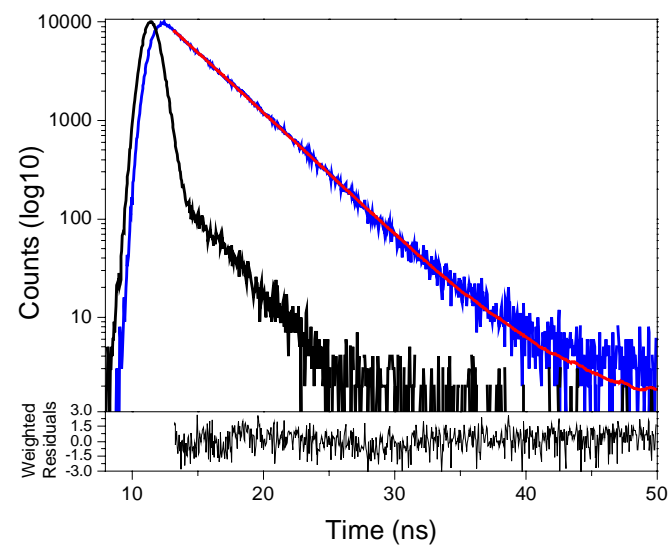

Figure S11. Decay of fluorescence of 6 monitored at $455 \mathrm{~nm}$ (solv.- $\left.\mathrm{CH}_{2} \mathrm{Cl}_{2}\right)\left(\chi^{2}\right.$ $=1.21$ ).

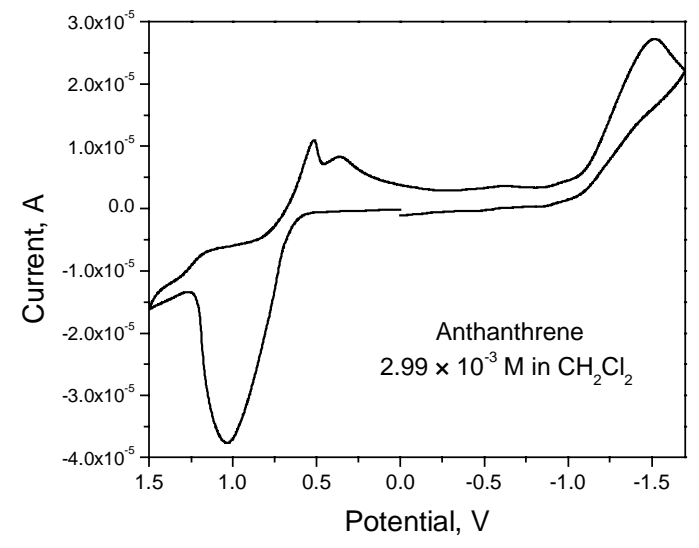

Figure S12. Cyclic voltammetry graph recorded from $\mathrm{CH}_{2} \mathrm{Cl}_{2}$ solution of $\mathbf{1}$ $\left(2.99 \times 10^{-3} \mathrm{M}\right)$.

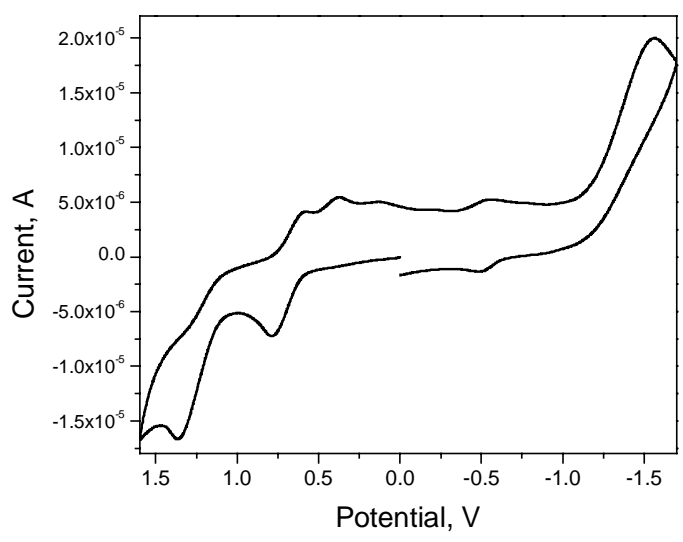

Figure S13. Cyclic voltammetry graph recorded from $\mathrm{CH}_{2} \mathrm{Cl}_{2}$ solution of 4 $\left(8.23 \times 10^{-4} \mathrm{M}\right)$.

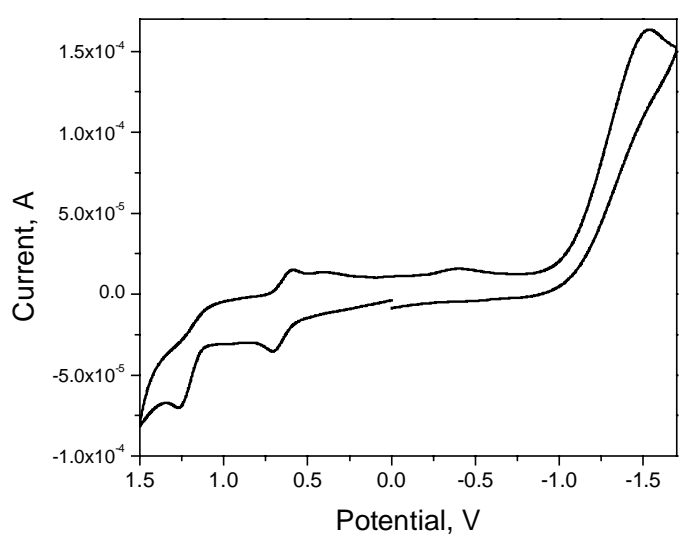

Figure S14. Cyclic voltammetry graph recorded from $\mathrm{CH}_{2} \mathrm{Cl}_{2}$ solution of $\mathbf{5}$ $\left(6.16 \times 10^{-4} \mathrm{M}\right)$. 